\title{
Questionable Effect of Crosshatching Incision in Septoplasty
}

\author{
Jung-Soo $\mathrm{Kim}^{1}$ (D) $\cdot$ Sung Jae $\mathrm{HeO}^{2}$ () \\ ${ }^{1}$ Department of Otorhinolaryngology-Head and Neck Surgery, Kyungpook National University Hospital, School of Medicine, Kyungpook National \\ University, Daegu; ' Department of Otorhinolaryngology-Head and Neck Surgery, Kyungpook National University Chilgok Hospital, \\ School of Medicine, Kyungpook National University, Daegu, Korea
}

Objectives. Crosshatching incision has been considered a useful method for correcting cartilaginous septal deviation. The aim of this study was to determine the utility and limitations of this approach.

Methods. This retrospective case-control study included 353 patients who underwent septoplasty performed by a senior surgeon between January 2004 and December 2010. Patients were classified into two groups according to whether crosshatching incision was performed $(n=151)$ during septoplasty or not $(n=202)$. All other techniques performed during septoplasty were identical. The parameters of surgical success (improvement of nasal obstruction, correction of deviation, and acoustic rhinometry results) and adverse effects were compared between the groups.

Results. There were no significant differences in the parameters of surgical success between the groups (improvement of nasal obstruction, $P=0.333$; correction of deviation, $P=0.608$; acoustic rhinometry results, $P=0.322$ for the difference in the minimal cross-sectional area; $P=0.919$ for difference in volume). Relative to patients who did not undergo the cross-hatching incision, patients with whom the technique was performed showed a significantly higher incidence of saddle nose (0/202 vs. 4/151 cases, $P=0.033)$ and overcorrection (0/202 vs. 5/151 cases, $P=0.014)$.

Conclusion. Crosshatching incision during septoplasty did not produce better surgical outcomes; however, it caused adverse effects such as saddle nose and overcorrection. Therefore, the use of crosshatching incision should be re-evaluated.

Keywords. Nasal Septum; Cartilage; Nasal Surgical Procedures; Reconstructive Surgical Procedures

\section{INTRODUCTION}

A variety of techniques can be employed in septoplasty; their use is determined according to the diverse types of nasal septal deviation and surgeon preferences. Such techniques include submucosal resection [1], crosshatching incision [2], wedge incision [3], suture method [4], batten graft [5], and so forth. Among these techniques, the advantages of crosshatching incision have been lauded by several biomechanical studies and it has been

\footnotetext{
- Received February 7, 2019

Revised June 16, 2019

Accepted June 28, 2019

- Corresponding author: Sung Jae Heo

Department of Otorhinolaryngology-Head and Neck Surgery, Kyungpook National University Chilgok Hospital, 807 Hoguk-ro, Buk-gu, Daegu 41404, Korea

Tel: +82-53-200-2166, Fax: +82-53-200-2027

E-mail: blueskyhsj@hanmail.net
}

widely adopted by numerous surgeons [2,6,7]. Crosshatching incision is a representative technique of the incisional method, which was advocated by Murakami et al. [2]. However, the experimental settings which demonstrated the usefulness of crosshatching incision are different from those in which actual surgeries are performed. The previous experiments did not consider the attachment of septal cartilage to the surrounding structures, the effect of gravity, the principle of L-strut preservation, or the rectangular shape of the nasal septal cartilage $[2,8]$. Although a theoretical framework of crosshatching incision features critical drawbacks, the technique is still regarded as a noble method of septoplasty.

The authors of the present study had used crosshatching incision as an indispensable septoplasty technique for about 3 years. However, we experienced unintended surgical results including undercorrection, overcorrection, and saddle nose; these outcomes engendered doubts concerning the usefulness of cross-

Copyright $@ 2020$ by Korean Society of Otorhinolaryngology-Head and Neck Surgery.

This is an open-access article distributed under the terms of the Creative Commons Attribution Non-Commercial License (https://creativecommons.org/licenses/by-nc/4.0)

which permits unrestricted non-commercial use, distribution, and reproduction in any medium, provided the original work is properly cited. 
hatching incision. We therefore performed an experimental study to reproduce the original experiments evincing the benefits of the technique under actual surgical settings in order to determine the utility of crosshatching incision [8]. As expected, crosshatching incision did not correct the deviation of septum in the actual surgical setting.

To date, no study has analyzed the effectiveness or drawbacks of crosshatching incision relative to a control group. We therefore compared surgical results between the performance of septoplasty with and without crosshatching incision to validate the alleged superiority of the former.

\section{MATERIALS AND METHODS}

\section{Participants}

Between January 2004 and December 2010, patients who underwent septoplasty conducted by a senior surgeon (JSK) in Department of Otorhinolaryngology-Head and Neck Surgery, Kyungpook National University Hospital were included in the present study. Main septoplasty technique consisted of an anchoring suture with or without crosshatching incision. Exclusion criteria were the following: (1) a follow-up period of less than a year; (2) insufficient chart records; (3) combined operation with rhinoplasty, endoscopic sinus surgery, or tumor surgery; and (4) other septoplasty techniques such as batten graft and extracorporeal septoplasty. Patients were classified into two groups according to the types of septoplasty technique with which their respective surgeries were performed: anchoring suture with crosshatching incision (incision group) or anchoring suture without crosshatching incision (non-incision group). The type of septoplasty technique was determined by the time at which the surgery was performed regardless of the shape of septal deviation: anchoring suture with crosshatching incision technique was used until 2007; afterward, anchoring suture without the crosshatching technique was employed on account of complications we had experienced, such as saddle nose and unsatisfactory surgical results. Therefore, there is no bias in the application of surgical technique depending on the shape of the septal deviation. This study was conducted with the approval from the Institutional Review Board of Kyungpook National University Hospital (IRB No. KNUH 2013-0030). Informed consent was exempt-

\section{H I}

- Crosshatching incision during septoplasty did not produce better surgical outcomes.

- Crosshatching incision had more adverse effects such as saddle nose and overcorrection.

- The use of crosshatching incision in septoplasty should be reevaluated. ed because this is a retrospective study.

\section{Parameters}

The preoperative degree of septal deviation and acoustic rhinometry value were reviewed to ascertain the differences between incision and the non-incision groups. Preoperative degree of septal deviation was classified into three categories using endoscopic examination: 1 , deviation of less than half of the total distance to the lateral nasal wall; 2 , deviation of more than half of but less than the total distance to the lateral nasal wall; and 3, deviation of the total distance to the lateral nasal wall [9]. Minimal cross-sectional area (MCA) and volume of preoperative acoustic rhinometry were analyzed.

Correction degree of deviation, improvement degree of obstruction, acoustic rhinometry value, operation duration, number of revision cases, and number of complications were analyzed to determine surgical outcome. Correction degree of deviation was rated on a 3-point numerical scale according to the assessment of a senior surgeon using endoscopic examination: 3 , well corrected; 2 , moderately corrected; and 1 , poorly corrected. Improvement degree of obstruction was rated by patients using a 3-point scale: 3, completely improved; 2 , partially improved; 1 , not improved. Acoustic rhinometry values (MCA and volume) were compared between preoperative and postoperative values measured on the convex side of the nasal cavity. Operation duration was measured from draping to nasal packing. The parameters of complications consisted of saddle nose, overcorrection, septal perforation, septal hematoma, septal abscess, synechia, and postoperative bleeding.

\section{Surgical technique}

Most septoplasties were performed under local anesthesia. Hemitransfixion incision was conducted on the concave side of nasal cavity. After flap elevation, we separated the septal cartilage from the septal bone and removed excessive portions. The septum was then repositioned to the midline of the nasal cavity. In the case that crosshatching incision was performed, the septal cartilage was scored on the deviated portion of concave side with a full-thickness incision. L-strut was preserved with a length of at least $1.5 \mathrm{~cm}$. Afterwards, an anchoring suture was started from the concave side of septum to penetrate the septal cartilage and mucosa at the most deviated portion with 4-0 polydioxanone (Fig. 1) [10]. Knots were made at the periosteum and soft tissues around the anterior nasal spine. After the completion of the anchoring suture, a quilting mattress suture was performed to prevent septal hematoma. Inferior turbinate surgery (radiofrequency volume reduction) was performed after septoplasty.

\section{Statistical analysis}

Data were analyzed using SPSS ver. 18.0 (SPSS Inc., Chicago, IL, USA). Mean age, follow-up period, acoustic rhinometry val- 

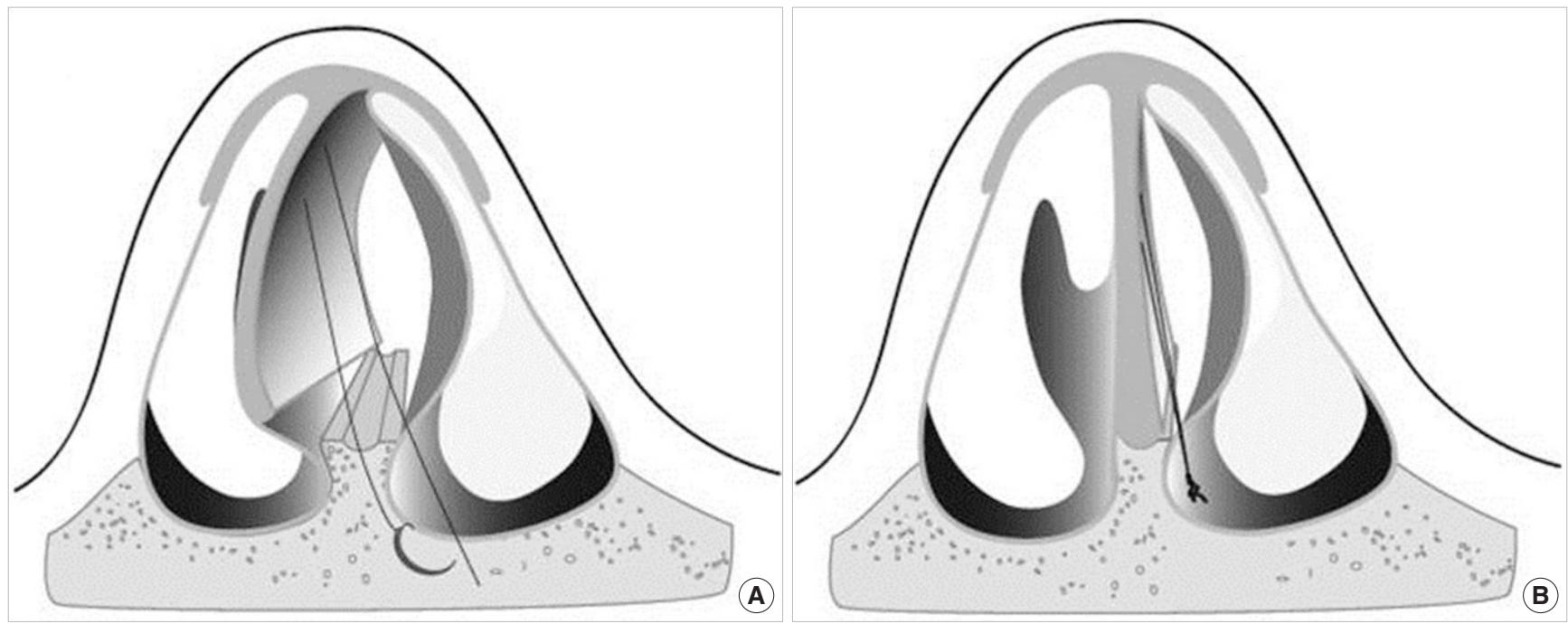

Fig. 1. Illustrations of anchoring suture technique. (A) An anchoring suture was started from the concave side of septum to penetrate the septal cartilage and mucosa at the most deviated portion with 4-0 polydioxanone. (B) Knots were made at the periosteum and soft tissues around the anterior nasal spine. Adopted from Song et al. J Rhinol. 2016;13:18-21 [10].

ue, and operation duration were tested using an unpaired $t$-test. Sex, case of revision surgery, and case of complications were tested with chi-square or Fisher's exact test. The Kruskal-Wallis test was used to analyze the degree of septal deviation, correction degree of deviation, and the improvement degree of nasal obstruction. Differences were regarded significant when the $P$ value was $<0.05$.

\section{RESULTS}

A total of 353 patients were included in this study: the numbers of men and women were 302 and 51, respectively; their mean age was $35.5 \pm 14.7$; and the mean period of postoperative follow-up was $15.9 \pm 6.3$ months. The numbers of patients in the incision and non-incision groups were 151 and 202, respectively. No demographic differences were found between the two groups (Table 1). The degree of septal deviation measured via both endoscopy and acoustic rhinometry did not reveal any significant difference between the groups.

The correction degree of septal deviation was not significantly different between the two groups $(2.91 \pm 0.28$ in the incision group and $2.89 \pm 0.31$ in the non-incision group, $P=0.608$ ) (Table 2). There were no significant differences in the improvement degree of nasal obstruction, operation duration, or acoustic rhinometry values between the two groups. Revision septoplasty was performed in three cases in both groups; the rate of required revision was not significantly different $(P=0.704)$.

After septoplasty, four cases of saddle nose were observed in the incision group, while the non-incision group lacked any such cases $(P=0.033)$ (Table 3). Overcorrection was observed in five cases of the incision group; no case of overcorrection was
Table 1. Comparison of demographic and preoperative data between the incision and non-incision groups

\begin{tabular}{lccc}
\hline Variable & $\begin{array}{c}\text { Incision group } \\
(n=151)\end{array}$ & $\begin{array}{c}\text { Non-incision } \\
\text { group }(n=202)\end{array}$ & $P$-value \\
\hline Sex (male:female) & $128: 23$ & $174: 28$ & 0.761 \\
Age $(\mathrm{yr})$ & $34.4 \pm 14.3$ & $36.4 \pm 15.0$ & 0.259 \\
Follow-up period (mo) & $16.5 \pm 7.0$ & $15.3 \pm 5.5$ & 0.171 \\
$\begin{array}{l}\text { Preoperative degree of septal } \\
\quad \text { deviation }\end{array}$ & $1.49 \pm 0.61$ & $1.55 \pm 0.58$ & 0.570 \\
$\begin{array}{l}\text { Preoperative acoustic rhinometry } \\
\quad \text { MCA }\end{array}$ & & & \\
$\quad$ Volume & $0.197 \pm 0.136$ & $0.184 \pm 0.154$ & 0.494 \\
\hline
\end{tabular}

Values are presented as mean \pm standard deviation.

MCA, minimal cross-sectional area.

Table 2. Comparison of surgical outcomes of septoplasty between the incision and non-incision groups

\begin{tabular}{|c|c|c|c|}
\hline Variable & $\begin{array}{l}\text { Incision group } \\
\quad(n=151)\end{array}$ & $\begin{array}{l}\text { Non-incision } \\
\text { group }(n=202)\end{array}$ & $P$-value \\
\hline Correction of deviation & $2.91 \pm 0.28$ & $2.89 \pm 0.31$ & 0.608 \\
\hline $\begin{array}{l}\text { Improvement of nasal } \\
\text { obstruction }\end{array}$ & $2.78 \pm 0.42$ & $2.81 \pm 0.40$ & 0.333 \\
\hline Operation duration (min) & $39.4 \pm 5.4$ & $38.3 \pm 5.0$ & 0.052 \\
\hline \multicolumn{4}{|l|}{ Acoustic rhinometry } \\
\hline MCA gap & $0.27 \pm 0.15$ & $0.29 \pm 0.15$ & 0.322 \\
\hline Volume gap ${ }^{a)}$ & $2.65 \pm 1.48$ & $2.62 \pm 1.52$ & 0.919 \\
\hline No. of revision cases & 3 & 3 & 0.704 \\
\hline
\end{tabular}

Values are presented as mean \pm standard deviation.

MCA, minimal cross-sectional area.

a) Volume gap is the difference of acoustic rhinometry between preoperative and postoperative values measured on the convex side of the nasal cavity. 
Table 3. Comparison of complications of septoplasty between the incision and non-incision groups

\begin{tabular}{lccc}
\hline Variable & $\begin{array}{c}\text { Incision group } \\
(\mathrm{n}=151)\end{array}$ & $\begin{array}{c}\text { Non-incision } \\
\text { group }(\mathrm{n}=202)\end{array}$ & P-value \\
\hline Saddle nose & 4 & 0 & 0.033 \\
Overcorrection & 5 & 0 & 0.014 \\
Synechia & 1 & 2 & 0.608 \\
Postoperative bleeding & 2 & 3 & 0.634 \\
Septal hematoma & 0 & 0 & $\mathrm{NA}$ \\
Septal perforation & 0 & 0 & $\mathrm{NA}$ \\
Septal abscess & 0 & 0 & $\mathrm{NA}$ \\
\hline
\end{tabular}

Values are number of cases.

NA, not available.

evinced in the non-incision group $(P=0.014)$. There were no significant differences in synechia and postoperative bleeding between the two groups $(P=0.608$ and $P=0.634$, respectively). No case of septal hematoma, perforation, and abscess developed in either group.

\section{DISCUSSION}

The incisional technique is widely regarded to be an effective method when performing septoplasty, and numerous surgeons advocate the use of the technique. The technique is based on the theory of an internal interlocked stress system described by Fry and Robertson [11] and Fry [12]. The outer layers of the cartilage are maintained in tension so that the intact cartilage is balanced by a net-zero system of forces [11]. When incision is employed to one side of the cartilage, the balance is broken and the cartilage bends toward the opposing side. Several experiments concluded that the partial-thickness incision on the concave side of the cartilage allows for the straightening of the deviated cartilage. In 1982, Murakami et al. [2] indicated a number of errors in Fry's experiments and insisted that the bending achieved by partial-thickness incision is insufficient to straighten the curved cartilage. They concluded that a full-thickness crosshatching incision on the concave side is necessary to straighten the curvature. ten Koppel et al. [6] subsequently validated Murakami's theory through a similar experiment.

However, the experiment performed by Murray [13] showed results that conflicted with the theory of Fry and colleague $[11,12]$. The lack of deviation of the traumatized human septal cartilage in the in-vitro experiment was not in accordance with the theory of interlocked stress. Lopatin [14] applied the interlocked stress theory to the septoplasty. They experienced unpredictable postoperative deformities in several cases, demonstrating that the biomechanical method of septoplasty does not apply to some cases. Gruber et al. [7] warned that the incisional technique could cause instability of the cartilage and scored cartilage could be completely collapsed. Min and Chung [15] reported that $1.8 \%$ of patients who underwent crosshatching inci- sion technique featured a saddle nose and introduced a modification of the incision's direction in order to reduce the weakening of the cartilage. In summary, the aforementioned studies indicate that the surgical outcome of crosshatching incision can be unpredictable and disappointing. Furthermore, the incision can weaken the cartilage and induce its instability.

Biomechanical properties of septal cartilage, scarring during the wound-healing process, and the thicknesses of septal cartilage differ widely across individuals. Moreover, since techniques are also differentially employed by surgeons, a precise incision to the planned depth of cartilage is hardly possible. As mentioned in the introduction, previous experiments did not consider the attachment of the septal cartilage to the surrounding structures, the effect of gravity, the principle of L-strut preservation, or the rectangular shape of the nasal septal cartilage $[2,8]$. Nevertheless, the crosshatching incision is still lauded as a novel, efficacious septoplasty technique. The authors of the present study therefore performed experiments that assessed the efficacy of the crosshatching incision technique under actual surgical conditions [8]. The results were disappointing and we concluded that the crosshatching incision might be ineffective for the correction of septal deviation. Although we have proved the ineffectiveness of the crosshatching incision in an animal experiment, a clinical investigation was necessary to validate the efficacy of the technique.

In this study, addition of the crosshatching incision to septoplasty did not induce better surgical outcomes. No difference in subjective and objective surgery results was observed between the incision and non-incision groups. However, saddle nose and overcorrection occurred more frequently in the incision group than in the non-incision group. Therefore, this study demonstrates that the crosshatching incision does not facilitate better outcomes but may rather increase the likelihood of the aforementioned complications. Seo et al. [16] reported the risk of crosshatching-incision induced overcorrection, especially among younger patients. Yang et al. [17] reported that $75 \%$ of septal deviations were corrected only by manipulating the bony septum. They emphasized the importance of the correction of the bony framework and the necessity of limiting the role of the crosshatching incision when performing septoplasty.

The most important factors that surgeons should consider are the stability of the nasal septum as well as the correction of deviation. A burgeoning trend in septoplasty surgery favors noninvasive methods. Reinforcement techniques, such as batten graft and suture methods, are increasingly more preferred than weakening techniques, including submucous resection and the incision method. Since crosshatching incision weakens the septal cartilage, it could increase the risk of saddle nose and overcorrection. Therefore, the additional use of batten graft or cyanoacrylate tissue adhesive is recommended if a surgeon utilizes the crosshatching technique.

This study is subject to the possible limitation of its being ret- 
rospective. Although a prospective case control study between the incision versus the non-incision groups might increase the power of evidence, the medical ethics of the authors precludes our performance of such research, as we have found negative evidences of crosshatching incision. Another possible limitation of the present study is time gap between the surgeries received by the incision and non-incision groups. Septoplasties of the incision group were performed between 2004 and 2006, whereas the surgeries of non-incision group were performed between 2007 and 2010. There is a possibility that proficiency of the surgeons affected the surgical outcomes. However, since the senior surgeon (JSK) began performing septoplasty in 1989 and had accrued ample experience by the time the incision surgeries were performed, proficiency may not have significantly influenced the results. In addition, since all septoplasty is performed with turbinate surgery, acoustic rhinometry results do not reflect only septoplasty. However, in general, septoplasty alone is not often performed because septal deviation is usually accompanied by hypertrophy of inferior turbinate $[18,19]$.

In conclusion, there are various surgical methods in septoplasty, and the selection of the proper surgical method is an important factor in the surgical outcome. This study demonstrated that the crosshatching incision did not produce better surgical outcomes and increased the rate of consequent complications. Therefore, it is necessary to reconsider the utility of crosshatching incision in order to enhance surgical outcome.

\section{CONFLICT OF INTEREST}

No potential conflict of interest relevant to this article was reported.

\section{ORCID}

Jung-Soo Kim https://orcid.org/0000-0002-0899-3794

Sung Jae Heo https://orcid.org/0000-0002-1388-8075

\section{AUTHOR CONTRIBUTIONS}

Conceptualization: all authors. Data curation: SJH. Formal analysis \& Methodology: all authors. Project administration \& Visualization: SJH. Writing - original draft, review \& editing: all authors.

\section{REFERENCES}

1. Killan G, Foster EE. The submucous window resection of the nasal septum.Ann Otol Rhinol Laryngol. 1905 Jun;14(2):363-93.

2. Murakami WT, Wong LW, Davidson TM. Applications of the biomechanical behavior of cartilage to nasal septoplastic surgery. Laryngoscope. 1982 Mar;92(3):300-9.

3. Lee JE, Jung HJ, Chang M, Jin HR. A novel wedge technique to correct the curved deviation of the cartilaginous nasal septum. Auris Nasus Larynx. 2014 Apr;41(2):190-4.

4. Shin JH, Lee MH, Kim YH, Kim SW, Kim SW, Cho JH, et al.Wedge resection and modified mattress suture for correcting anterior septal deviation: how we do it. Clin Otolaryngol. 2011 Oct;36(5):504-9.

5. Chung YS, Seol JH, Choi JM, Shin DH, Kim YW, Cho JH, et al. How to resolve the caudal septal deviation? Clinical outcomes after septoplasty with bony batten grafting. Laryngoscope. 2014 Aug;124(8): 1771-6.

6. ten Koppel PG, van der Veen JM, Hein D, van Keulen F, van Osch GJ, Verwoerd-Verhoef HL, et al. Controlling incision-induced distortion of nasal septal cartilage: a model to predict the effect of scoring of rabbit septa. Plast Reconstr Surg. 2003 May;111(6):1948-57.

7. Gruber RP, Nahai F, Bogdan MA, Friedman GD. Changing the convexity and concavity of nasal cartilages and cartilage grafts with horizontal mattress sutures. Part II: clinical results. Plast Reconstr Surg. 2005 Feb;115(2):595-606.

8. Heo SJ, Kim JS. Crosshatching incision technique in septoplasty: experimental outcomes under actual surgical settings. Auris Nasus Larynx. 2016 Oct;43(5):518-23.

9. Jin HR, Lee JY, Jung WJ. New description method and classification system for septal deviation. J Rhinol. 2007 May;14(1):27-31.

10. Song SH, Nam WH, Kim JS. Anchoring suture for correction of septal deviation. J Rhinol. 2006 Apr;13(1):18-21.

11. Fry H, Robertson WV. Interlocked stresses in cartilage. Nature. 1967 Jul;215(5096):53-4.

12. Fry HJ. Interlocked stresses in human nasal septal cartilage. Br J Plast Surg. 1966 Jul;19(3):276-8.

13. Murray JA. The behaviour of nasal septal cartilage in response to trauma. Rhinology. 1987 Mar;25(1):23-7.

14. Lopatin AS. Do laws of biomechanics work in reconstruction of the cartilaginous nasal septum? Eur Arch Otorhinolaryngol. 1996;253 (4-5):309-12.

15. Min YG, Chung JW. Cartilaginous incisions in septoplasty. ORL J Otorhinolaryngol Relat Spec. 1996 Jan-Feb;58(1):51-4.

16. Seo MC, Heo SC, Chung YS, Lee BJ. Overcorrected septums as a complication of septoplasty. Korean J Otolaryngol-Head Neck Surg. 2001 Jun;44(6):628-32.

17. Yang JW, Kim SI, Kwon JW, Park DJ. Are cross-hatching incisions mandatory for correction of cartilaginous septal deviation? Clin Exp Otorhinolaryngol. 2008 Mar;1(1):20-3.

18. Lee DC, Jin SG, Kim BY, Yoo S, Han S, Lee YJ, et al. Does the effect of inferior turbinate outfracture persist? Plast Reconstr Surg. 2017 Feb;139(2):386e-391e.

19. Kim DH, Park HY, Kim HS, Kang SO, Park JS, Han NS, et al. Effect of septoplasty on inferior turbinate hypertrophy. Arch Otolaryngol Head Neck Surg. 2008 Apr;134(4):419-23. 